Original Article

\title{
COMPARATIVE IN VITRO ANTI-BIOFILM EFFICACY OF PHYTOSYNTHESIZED IRON AND SILVER NANOPARTICLES
}

\section{S. GOKUL BRINDHA ${ }^{a}$, V. S. HANSIYA ${ }^{\mathrm{b}}$, P. UMA MAHESWARI', N. GEETHA ${ }^{\mathrm{d} *}$}

a,b,cResearch Scholars of Department of Botany, Bharathiar University, Coimbatore 641 046, Tamil Nadu, India, d*Faculty of Department of Botany, Bharathiar University, Coimbatore 641 046, Tamil Nadu, India

Email: geethadrbot@gmail.com

Received: 23 Jul 2019, Revised and Accepted: 22 Oct 2019

\section{ABSTRACT}

Objective: The objective of the work was to evaluate the efficacy of anti-biofilm activity of green synthesized silver and iron oxide nanoparticles comparatively.

Methods: Nanoparticles were synthesized using a rapid, single-step and completely by a green biosynthetic method employing aqueous leaf extracts of Moringa oleifera Lam. The synthesized nanoparticles were characterized by UV-Vis spectrophotometry and X-Ray Diffraction. Bacterial strains used in this study included Staphylococcus epidermidis and Pseudomonas aeruginosa. The biofilm reduction was evaluated through ring test using crystal violet as a staining agent.

Results: Colour change was observed after half an hour, which indicated the formation of silver and iron nanoparticles. Synthesis of nanoparticles was confirmed by UV and XRD. The anti-biofilm forming ability of AgNPs and FeNPs were compared with standard antibiotic. It was found that FeNPs showed more biofilm destruction ability (58\%) for S. compared to P. aeruginosa (50\%) and standard (30\%). Whereas, AgNPs displayed significant biofilm destruction ability (78\%) for P. aeruginosa compared to S. epidermidis (43\%) and standard (34\%).

Conclusion: Based on the results obtained in this investigation, it is concluded that FeNPs have anti-biofilm activity against $S$. epidermidis whereas AgNPs have anti-biofilm activity against $P$. aeruginosa.

Keywords: Anti-biofilm, Silver nanoparticles, Iron nanoparticles, P. aeruginosa, S. epidermidis

(C) 2020 The Authors. Published by Innovare Academic Sciences Pvt Ltd. This is an open-access article under the CC BY license (http://creativecommons.org/licenses/by/4.0/) DOI: http://dx.doi.org/10.22159/ijap.2020v12i1.35047 Journal homepage: https://innovareacademics.in/journals/index.php/ijap

\section{INTRODUCTION}

Medicinal plants have been a primary source of therapeutic agents since ancient times to cure various human diseases. As the phytomedicine is healthier than synthetic products, the discovery of new drugs for various diseases from a natural source is still considered important. Due to the occurrence of therapeutic agents and different compounds, plants are used as medicine in various countries and are the source of many powerful and potent phytomedicines [1]. More than $25 \%$ of the approved drugs in the world are prepared from a variety of plant materials as roots, leaves, bark, and stems etc [2]. Using the plants as medicine have greater advantages including low toxicity, long-time oral consumption, low cost, and relatively lower toxicity even at higher dose. Photosynthesis of nanoparticles has contributed for the development of a relatively new and largely unexplored area of research in nanotechnology.

At present, there is a growing demand for nanoparticles due to their broad applications in various fields, such as therapeutics, diagnostics, surgical devices and nanomedicine based antimicrobial agents, catalysis and sensor technology in analytical chemistry $[3,4]$. However, the development of the simple and eco-friendly process for synthesis of nanomaterials would help in increasing further interest towards the application of metallic nanoparticles. Silver ions and silver-based compounds are toxic to microorganisms and this makes silver an admirable choice for manifold roles in the medical field. Silver is considered as one of the most widespread antimicrobial substances that exhibit low toxicity in human cells and has diverse roles both in in vitro and in vivo applications. Iron oxide has received specific notice because of their diverse scientific and technological applications such as biosensor [5], antimicrobial activity [6], food preservation [7], magnetic storage media, ferrofluids, magnetic resonance imaging, magnetic refrigeration, cell sorting, targeted drug delivery, and hyperthermic cancer treatments [8]. Besides, it has also been widely used in biomedical research because of its biocompatibility and magnetic properties [9].

In recent years, the number of infections coupled with antibiotic- resistant bacteria has increased. Many of these infections are caused by microorganisms growing in biofilms. Both gram-positive and gram-negative bacteria can form biofilms on indwelling medical devices such as catheters, mechanical heart valves and prosthetic joints. The most common biofilm-forming bacteria linked with human diseases Enterococcus faecalis, Staphylococcus aureus, Klebsiella pneumoniae, Staphylococcus epidermidis, Staphylococcus viridans, Proteus mirabilis, Pseudomonas aeruginosa [10]. Iron oxide nanoparticles were synthesized using Lactobacillus fermentum isolates [11]. These nanoparticles had an antibacterial and antibiofilm effect on coated catheters. Successfully synthesized Fe nanoparticles using the Annona squamosa leaf extract showed their inhibitory effect on Pseudomonas aeruginosa biofilm [12].

The increase biofilm resistance to conventional treatments has forced the need to search for new control strategies [13]. The seek for greener and safer alternatives than antibiotics and chemical preservatives is ongoing, especially in the upcoming context of phytomedicine. Plant-based antimicrobials are widely used on the perception of their safety and long history of their use. Moringa oleifera Lam. is one such plant that has received much publicity for its huge uses. The flavonoids extracted from its seed coat exhibited inhibitive potential as well as disruptive activities against biofilm formation [14]. It has also been for treating against buccal cavity or intestinal lesions inhabiting biofilm-forming pathogenic bacteria [15]. So far, there is no comparative study for the assessment in vitro biofilm efficacy of silver and iron nanoparticles synthesized using Moringa oleifera leaf extract. Therefore, this study was aimed to synthesized and characterize silver and iron nanoparticles and to evaluate the antibiofilm potential of these synthesized nanoparticles using gram-positive bacterium Staphylococcus aureus and gramnegative bacterium Pseudomonas aeruginosa.

\section{MATERIALS AND METHODS}

Chemicals

Chemicals such as silver nitrate $\left(\mathrm{AgNO}_{3}\right)$ and Ferric chloride $\left(\mathrm{FeCl}_{3}\right)$ 
were obtained from Sigma-Aldrich (Bangalore) and crystal violet was procured from Hi-Media (Mumbai).

\section{Collection and processing of the sample}

Fresh leaves were collected from M. oleifera which are grown in Bharathiar University Campus, Coimbatore, Tamil Nadu, India. The collected plant leaves were authenticated (BSI/SRC/5/ 23/2018/Tech/2855) by Scientist, Botanical Survey of India, Southern Regional Centre, TNAU, Coimbatore (authentication certificate enclosed). The sample was washed thoroughly to remove adhering dust and soil particles and then dried under shade condition for two weeks. The dried leaves were ground into a fine powder and stored at $4{ }^{\circ} \mathrm{C}$ for experimental studies.

\section{Plants extract preparation}

Five gram of the leaf powder was taken and mixed well with $100 \mathrm{ml}$ distilled water. Then, the extract was boiled for 20 min and allowed to cool. After cooling, the extract was filtered using Whatman No.1 filter paper and then extract was made to $100 \mathrm{ml}$ using distilled water $[16,17]$.

\section{Preparation of silver nitrate and ferric chloride solutions}

Silver nitrate and ferric chloride solutions were prepared separately for various concentrations such as $1 \mathrm{mmol}, 2 \mathrm{mmol}, 3 \mathrm{mmol}, 4 \mathrm{mmol}$ and $5 \mathrm{mmol}$ using deionized water.

\section{Synthesis of silver nanoparticles (AgNPs) and Iron nanoparticles (FeNPs)}

AgNPs and FeNPs were synthesized separately by mixing $10 \mathrm{ml}$ of a plant extract with $90 \mathrm{ml}$ of various concentrations of silver nitrate and ferric chloride solutions. The mixed solutions were heated for $10 \mathrm{~min}$ at $50{ }^{\circ} \mathrm{C}$ with continuous stirring . After heating, the solutions were kept under the dark conditions for 30 min incubation.

\section{Colour change}

After half an hour, the colour change was observed in all the reaction mixtures, which contain various concentrations of silver nitrate and ferric chloride.

\section{Characterization of nanoparticles}

\section{UV-Vis analysis}

After incubation, a small aliquot of each mixture was subjected to UV-Vis spectrometer for verifying the biosynthesis of silver and iron nanoparticles.

\section{X-ray diffraction (XRD) analysis}

After confirming nanoparticle synthesis by UV-Vis spectroscopy analysis, the reaction mixture was transferred into a sterile centrifuge tube and centrifuged at $8000 \mathrm{rpm}$ for $10 \mathrm{~min}$. The nanoparticle pellet was purified using sterile distilled water for thrice and air-dried pellets used for XRD analysis.

\section{Collection and maintenance of bacterial strains}

Microbial cultures such as Staphylococcus epidermidis (MTCC 2639) and Pseudomonas aeruginosa (MTCC 741) were purchased from Microbial Type Culture Collection (MTCC), Institute of Microbial technology (IMTECH), Chandigarh, India. The subculture for each microbial strain was done using Muller Hinton agar medium. The culture was incubated at $37^{\circ} \mathrm{C}$ for $16 \mathrm{~h}$.

\section{Biofilm formation assessment by crystal violet assay}

The antibiofilm activity was done by pouring $4 \mathrm{ml}$ of Muller Hinton broth in the sterilized glass tubes. One $\mathrm{ml}$ of each bacterial strain was added and to which the synthesized silver and iron nanoparticles were added at various concentrations i. e $10 \mu \mathrm{l}, 20 \mu \mathrm{l}, 30 \mu \mathrm{l}, 40 \mu \mathrm{l}, 50 \mu \mathrm{l}$ from the stock solution of $1 \mathrm{mg} / 1 \mathrm{ml}$. Then the tubes were incubated in an orbital shaker for $24 \mathrm{~h}$ at $37^{\circ} \mathrm{C}$. After incubation, the content of each tubes was gently removed. Tubes were washed with $5 \mathrm{ml}$ of sterile distilled water and allowed to dry for $5 \mathrm{~min} .0 .2 \%$ crystal violet was added and tubes were incubated for 30-45 min. After incubation, crystal violet was discarded and allowed to air dry. After drying, 95\% ethanol was added and OD was taken at $595 \mathrm{~nm}$ using spectrophotometer. The percentage inhibition of biofilm activity was calculated using the following formula:

$$
\% \text { inhibition of biofilim activity }=\frac{\mathrm{OD} \text { of Control-OD of Test }}{\mathrm{OD} \text { of Control }} \mathrm{X} 100
$$

\section{Statistical analysis}

The efficiency of biosynthesized AgNPs and FeNPs against bacterial growth is analyzed by applying a statistical tool (past 3).

\section{RESULTS \\ Colour change}

The plant extract of M. oleifera was used to synthesize AgNPs. After mixing leaf extract with various concentrations of $\mathrm{AgNO}_{3}$ and $\mathrm{FeCl}_{3}$, the mixtures were kept at dark condition. During half an hour incubation, a colour change was observed from light yellow to reddish-brown for solution with AgNPs and from pale yellow to dark yellow for the solution with FeNPs. Colour change has been observed for all the concentrations of $\mathrm{AgNO}_{3}$ and $\mathrm{FeCl}_{3}$ when added to plant extracts after half an hour incubation. Among five concentrations, $1 \mathrm{mmol}$ concentration reaction mixture has been taken for further studies. The formation of silver and iron oxide nanoparticles was primarily confirmed by visual colour change.

\section{UV-Vis characterization}

Aliquots were taken from a reaction mixture containing $1 \mathrm{mmol}$ concentration of $\mathrm{AgNO}_{3}$ and $\mathrm{FeCl}_{3}$ separately and OD was taken between $250-800 \mathrm{~nm}$ with a UV-Vis spectrophotometer at a resolution of $1 \mathrm{~nm}$ to determine the reduction rate of silver ions and ferric chloride ions. It is observed that the synthesized AgNPs displayed a clear SPR band at $400 \mathrm{~nm}$, which confirms the reduction of silver ion to metallic silver (fig. 1). It is noted that the synthesized FeNPs showed a clear SPR band at $404 \mathrm{~nm}$ which confirms the reduction of ferric ion to metallic iron (fig. 2).

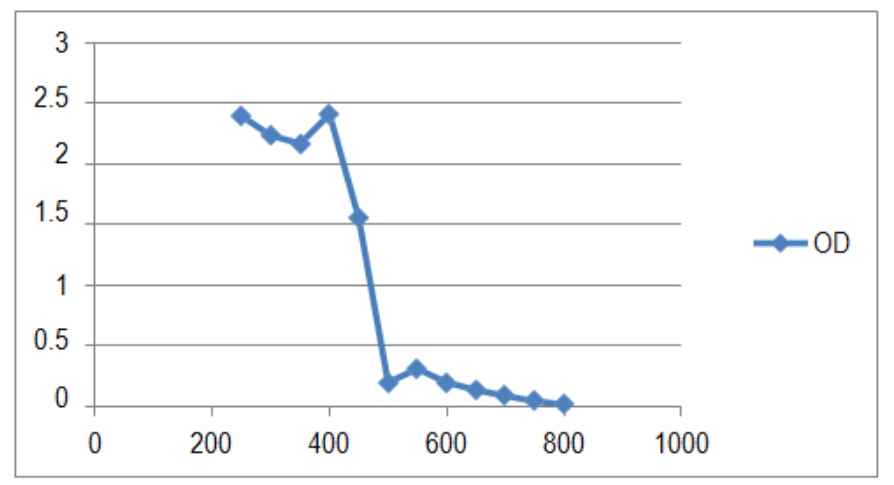

Fig. 1: UV-Vis absorption spectrum of AgNPs synthesized using $1 \mathrm{mmol}^{\mathrm{AgNO}_{3}}$ 


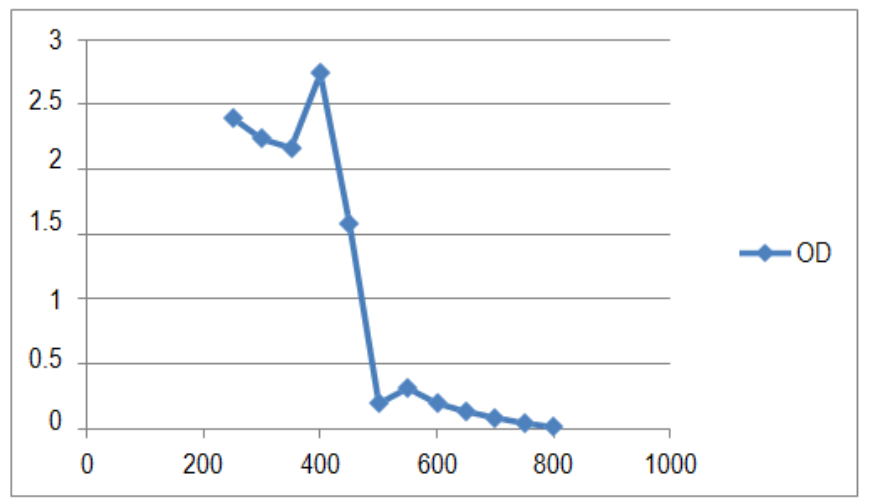

Fig. 2: UV-Vis absorption spectrum of FeNPs synthesized using 1 mmol $\mathrm{FeCl}_{3}$

For AgNPs, a peak at $400 \mathrm{~nm}$ suggests that the NPs were dispersed in the aqueous solution with no evidence of aggregation. When absorbance was taken after $24 \mathrm{~h}$ of incubation, no change was found in the absorbance. It indicates the stability of AgNPs. The peak for FeNPs at $404 \mathrm{~nm}$ shows the interaction of the leaf extract with the iron nanoparticles.

\section{X-ray diffraction}

Analysis through X-ray diffraction was carried out to confirm the crystalline nature of the AgNPs. A comparison of XRD spectrum with the standard confirmed the metallic silver formed in the reaction mixture, as evidenced by the peaks at 2-theta values of 14.402, $28.93,31.89,32.28,37.12,40.25,46.40,47.990$ and 49.71 corresponding to (174), (360), (315), (162), (296), (135), (84), (72) and (75) Bragg reflections, respectively shown in fig. 3 and table 1 . Analysis through X-ray diffraction was carried out to confirm the crystalline nature of the FeNPs. A comparison of XRD spectrum with the standard confirm the metallic iron formed in the reaction mixture, as evidenced by the peaks at 2-theta values of 14.239 , $20.030,28.82,29.39,32.163,40.06,42.47,46.20$ and 47.79 corresponding to (133), (177), (113), (131), (206), (141), (189), (115) and (177) Bragg reflection, respectively shown in fig. 4 and table 2. XRD spectrum AgNPs confirmed that the synthesized NPs were in the form of nanocrystals and the Debye-Scherrer equation shows the particle size of AgNPs is $30 \mathrm{~nm}$. Using XRD results, the particles of the FeNPs were found to be agglomerates in nature due to magnetic properties and average diameter was found to be $7 \mathrm{~nm}$ by applying Scherrer equation.

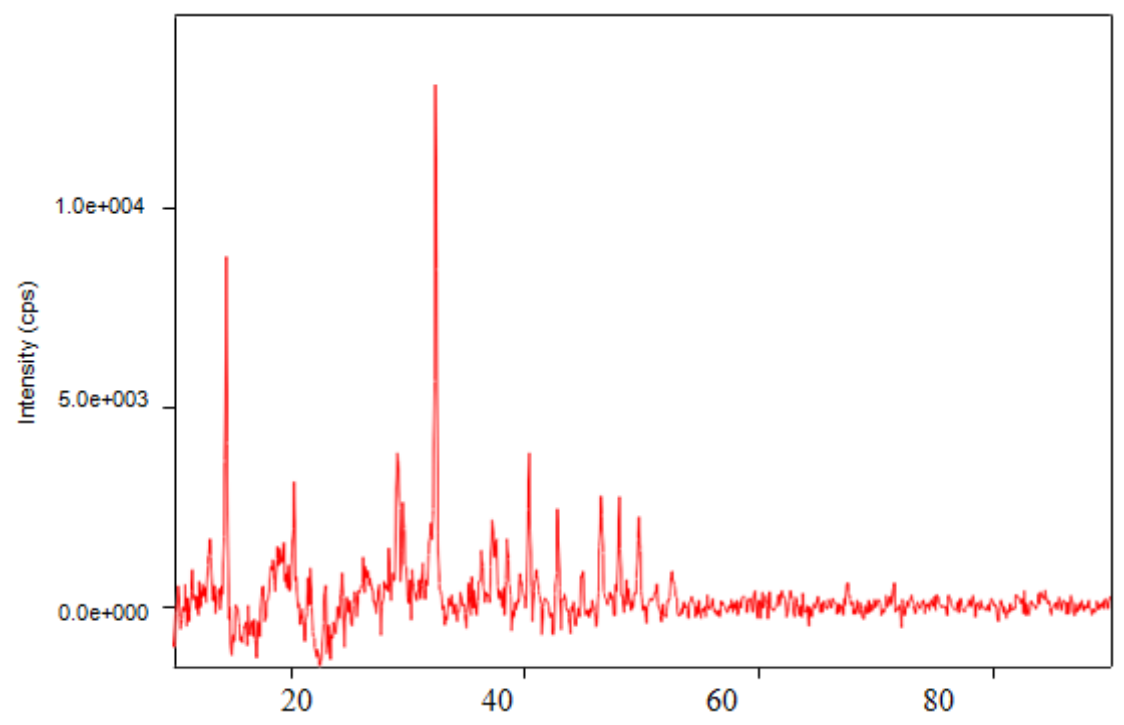

Fig. 3: XRD pattern of synthesized AgNPs

Table 1: Peak values for AgNPs

\begin{tabular}{|c|c|c|c|c|c|c|c|}
\hline No. & 2-theta (deg) & d(ang.) & Height(cps) & FWHM(de) & Int. I(cpsdeg) & Int. W(deg) & Asym. factor \\
\hline 1 & $14.402(12)$ & $6.145(5)$ & $6304(103)$ & $0.15(3)$ & $1416(174)$ & $0.22(3)$ & $1(3)$ \\
\hline 2 & $28.93(5)$ & $3.083(5)$ & 2088(59) & $0.66(9)$ & $1856(360)$ & $0.9(2)$ & $0.22(14)$ \\
\hline 3 & $31.89(7)$ & $2.804(6)$ & $868(38)$ & $0.5(3)$ & $796(315)$ & $0.9(4)$ & $5(26)$ \\
\hline 4 & $32.28(3)$ & $2.771(2)$ & $10926(135)$ & $0.15(2)$ & $2419(162)$ & $0.221(18)$ & $0.6(3)$ \\
\hline 5 & $37.12(13)$ & $2.420(8)$ & $1150(44)$ & $0.7(3)$ & $1634(296)$ & $1.4(3)$ & $0.4(6)$ \\
\hline 6 & $40.25(3)$ & $2.2385(16)$ & $6932(107)$ & $0.06(4)$ & $808(135)$ & $0.12(2)$ & $1.2(13)$ \\
\hline 7 & $46.40(8)$ & $1.955(3)$ & $2156(60)$ & $0.24(4)$ & $601(84)$ & $0.28(5)$ & $1.0(2)$ \\
\hline 8 & $47.990(15)$ & $1.8942(5)$ & $2512(65)$ & $0.12(6)$ & $450(72)$ & $0.18(3)$ & $3(51)$ \\
\hline 9 & $49.71(2)$ & $1.8326(7)$ & $1823(55)$ & $0.20(4)$ & $525(75)$ & $0.29(5)$ & $5(16)$ \\
\hline
\end{tabular}




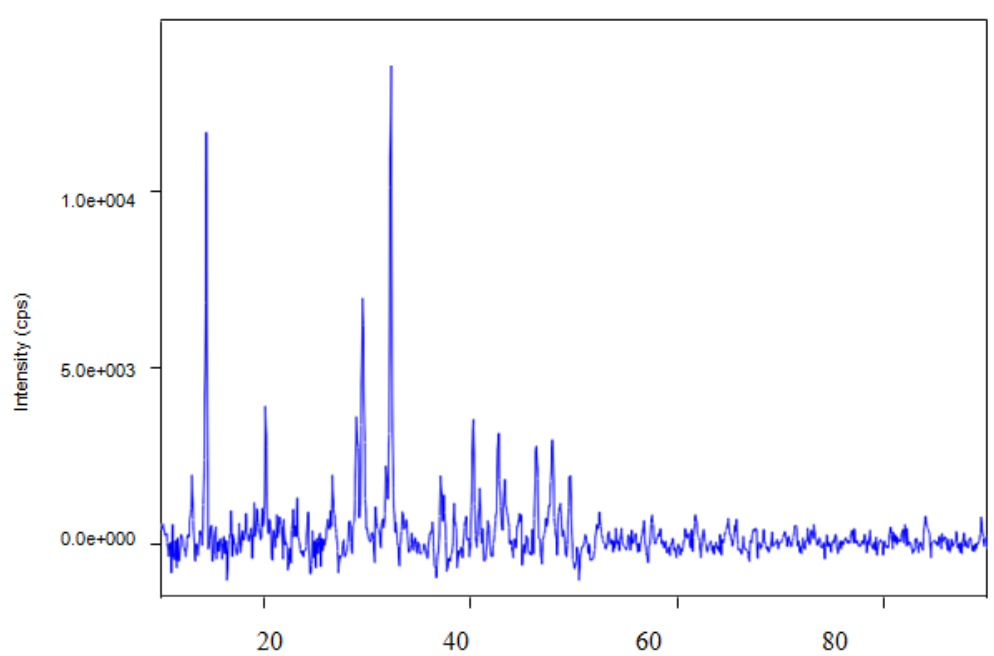

Fig. 4: XRD pattern of synthesized FeNPs

Table 2: Peak values for FeNPs

\begin{tabular}{|c|c|c|c|c|c|c|c|}
\hline No. & 2theta(deg) & d(ang.) & Height(ps) & FWHM(deg) & Int. I(cpsdeg) & Int. W(deg) & Asym. Factor \\
\hline 1 & $14.239(5)$ & $6.215(2)$ & $9319(125)$ & $0.132(14)$ & $1709(133)$ & $0.183(1)$ & $0.4(14)$ \\
\hline 2 & $20.030(19)$ & $4.429(4)$ & $2789(68)$ & $0.21(17)$ & $1067(177)$ & $0.38(7)$ & $2(7)$ \\
\hline 3 & $28.82(4)$ & $3.096(4)$ & $2597(66)$ & $0.28(5)$ & $949(113)$ & $0.37(5)$ & $0.7(4)$ \\
\hline 4 & $29.39(4)$ & $3.037(4)$ & $5275(94)$ & $0.24(2)$ & $1665(131)$ & $0.32(3)$ & $0.6(4)$ \\
\hline 5 & $32.163(6)$ & $2.7807(5)$ & $11394(138)$ & $0.17(5)$ & $2874(206)$ & $0.25(2)$ & $1(5)$ \\
\hline 6 & $40.06(2)$ & $2.2488(12)$ & $3829(80)$ & $0.13(5)$ & $802(141)$ & $0.21(4)$ & $0(5)$ \\
\hline
\end{tabular}

\section{Anti-biofilm assay}

The biosynthesized AgNPs and FeNPs were tested against two different bacterial strains, S. epidermidis and compared with standard antibiotic azithromycin. The nanoparticles were used in different concentrations $(10-50 \mu \mathrm{g} / \mathrm{ml}$ DMSO) for the anti-biofilm assay. The staining agent crystal violet helps for the determination of the presence of biofilm in ring form. When the AgNPs and FeNPs are used at low concentrations $(10-30 \mu \mathrm{g} / \mathrm{ml})$, the biofilm shows more density than higher concentrations $(40-50 \mu \mathrm{g} / \mathrm{ml})$. Of various concentrations, $50 \mu \mathrm{g} / \mathrm{ml}$ shows comparatively higher anti-biofilm activity. The adherence of bacterial biofilm to the walls of the test tubes shows violet patches upon the test tubes. Biofilm formation was considered positive when visible film lined the wall and bottom of the tube. Ring formation at the air-liquid interface was not indicative of biofilm formation.

\section{Statistical analysis}

The efficiency of biosynthesized AgNPs and FeNPs against bacterial growth is analyzed by applying statistical tool (SPSS) and analyzed results were given in table 3 . The anti-biofilm forming ability of AgNPs and FeNPs are compared with standard antibiotic. In the case of $S$. epidermidis FeNPs shows significant $(\mathrm{p}<0.05 \%)$ biofilm destruction ability (58\%) compared to AgNPs (56\%). The antibiotic shows only $38 \%$ efficiency. In the case of $P$. aeruginosa, AgNPs $(78 \%)(p<0.05 \%)$ shows higher antibiofilm activity than FeNPs $(43 \%)$ and antibiotics (34\%). From this data, it can be concluded that FeNPs are found more suitable for the destruction of biofilms caused by S. epidermidis and AgNPs are found more efficient for the destruction of biofilm caused by P. aeruginosa.

Table 3: Efficiency of biosynthesized AgNPs and FeNPs on bacterial growth inhibition

\begin{tabular}{|c|c|c|c|c|c|c|c|}
\hline \multirow{3}{*}{$\begin{array}{l}\text { Name of the plant } \\
\text { M. oleifera }\end{array}$} & \multicolumn{7}{|c|}{ Name of the microorganism } \\
\hline & \multirow[t]{2}{*}{ Conc. $\mu \mathrm{g} / \mathrm{ml}$} & \multicolumn{3}{|c|}{ S. epidermidis } & \multicolumn{3}{|c|}{ P. aeruginosa } \\
\hline & & AgNPs & FeNPs & Antibiotics & AgNPs & FeNPs & Antibiotics \\
\hline & 10 & $10 \pm 2^{*}$ & $5 \pm 2$ & $10 \pm 2$ & $10 \pm 7$ & $9 \pm 6$ & $7 \pm 6$ \\
\hline & 20 & $10 \pm 3$ & $20 \pm 2$ & $10 \pm 3$ & $30 \pm 7$ & $10 \pm 8$ & $10 \pm 2$ \\
\hline & 30 & $20 \pm 5$ & $23 \pm 7$ & $18 \pm 7$ & $50 \pm 8$ & $20 \pm 7$ & $20 \pm 2$ \\
\hline & 40 & $40 \pm 8$ & $30 \pm 7$ & $20 \pm 7$ & $60 \pm 5$ & $30 \pm 6^{b}$ & $30 \pm 9 b$ \\
\hline & 50 & $50 \pm 6^{b}$ & $50 \pm 8^{a}$ & $30 \pm 8^{c}$ & $70 \pm 8^{\mathrm{a}}$ & $35 \pm 8^{b}$ & $32 \pm 2^{c}$ \\
\hline
\end{tabular}

*Values followed by different letters indicate significant difference. The data represent the mean between \pm SD $(\mathrm{p}<0.05)$, comparison by DMRT, Where $a>b>c$.

\section{DISCUSSION}

There are several ways for characterizing nanoparticles. The first and most convenient way is the colour change of solution [18]. During synthesis of silver and iron nanoparticles, addition of leaf extract of $M$. olifera into aqueous solutions of silver nitrate and ferric chloride led to the change in the colour of the solution from yellow to reddish-brown for silver nanoparticles synthesis and pale yellow to dark yellow for iron particle synthesis within half an hour dark incubation due to excitation of surface plasmon vibrations in silver nanoparticles [19] and in iron nanoparticles [20]. The surface plasmon resonance of AgNPs showed a peak centered near $400 \mathrm{~nm}$ at UV-vis spectra which corresponds to the absorbance of AgNPs. This peak indicates the reduction of silver nitrate into AgNPs. For 
synthesis of iron nanoparticles, peak observed at around $404 \mathrm{~nm}$ which may due to surface plasma resonance of electrons of metal. There was an increase in intensity till the sixth hour as a function of reaction time without any shift in the peak wavelength for synthesis of iron nanoparticles [18]. On examining XRD pattern of silver nanoparticles, the prominent peaks at $14.402,28.93,31.89,32.28$, $37.12,40.25,46.40,47.990$ and 49.71 represents the (174), (360), (315),(162), (296), (135), (84), (72) and (75) Bragg's reflections of the face-centered cubic structure of silver, respectively [21]. The Xray diffraction patterns obtained for the FeNPs synthesised using Moringa leaf extract exhibit strong peaks with $2 \theta$ values of 14.239 , $20.030,28.82,29.39,32.163,40.06,42.47,46.20$ and 47.79 corresponding to the value of (133),(177), (113), (131), (206), (141), (189), (115) and (177) that denote crystalline phase of FeNPs [22]. In the present investigation, anti-biofilm forming ability of AgNPs and FeNPs are compared with the standard antibiotic. It was found that for $S$. epidermidis FeNPs shows significant biofilm distruction ability [23] Whereas, AgNPs shows, significant biofilm destruction ability for P. aeruginosa [24]. Nanoparticles have high penetrating ability than antibiotics [25]. The development of antimicrobial resistance is a universal obstacle that necessitates the innovation of more effective and safe antimicrobial alternatives [26]. Generally it is observed that gram-negative bacterial strains more vulnerable to AgNPs rather than gram-positive bacterial strains [27] which is also evidenced in the present study.

\section{CONCLUSION}

In the present investigation, an attempt was made to compare the efficiency of AgNPs and FeNPs for the destruction of biofilm formation against $S$. epidermidis and $P$. aeruginosa. Even at low concentration of nanoparticles $(10-50 \mu \mathrm{g} / \mathrm{ml})$, significant antibiofilm activity has been observed which proves the medicinal properties of M. oleifera leaves. Future studies would include more concentrations of these synthesized nanoparticles to understand anti-biofilm effect for various microorganisms.

\section{ACKNOWLEDGMENT}

The authors acknowledge the financial support provided by UGCSAP and DST-FIST, INDIA for carrying out this research.

\section{AUTHORS CONTRIBUTIONS}

All the authors have contributed equally.

\section{CONFLICT OF INTERESTS}

None

\section{REFERENCES}

1. Srivastava J, Lambert J, Vietmeyer N. Medicinal plants: an expanding role in development. World Bank Tech Pap 1996;320:1-36.

2. Graham JG, Quinn ML, Fabricant DS, Farnsworth NR. Plants used against cancer-an extension of the work of Jonathan Hartwell. J Ethopharmacol 2000;73:347-77.

3. Sobha K, Surendranath K, Meena V, Jwala KT, Swetha N, Latha KSM. Antibacterial activity of $\mathrm{ZnO}$ nanoparticle on gram-positive and gram-negative bacteria, J Biotechnol 2010;4:1368-73.

4. Gholivand MB, Pashabadi A, Azadbakht A, Menati S. A nanostructured Ni(II)-ACDA modified gold nanoparticle selfassembled electrode for electrocatalytic oxidation and determination of tryptophan. Electrochim Acta 2011; 56:4022-30.

5. Berry CC, Curtis ASG. Functionalization of magnetic nanoparticles for applications in biomedicine. J Phys D Appl Phys 2003;36:198-206.

6. Azam A, Amed AS, Oves M, Khan MS, Habib SS, Memic A. Antimicrobial activity of metal oxide nanoparticles against gram-positive and gram-negative bacteria: a comparative study. Int J Nanomed 2012;7:6003-9.

7. Chan DCF, Kirpotin DB, Bunn PA. Synthesis and evaluation of colloidal magnetic iron oxides for the site-specific radiofrequency induced hyperthermia of cancer. J Magn Magn Mater 1993;122:374-8.

8. Beets Tan RGH, Beets GL, Bortslap ACW, Oei TK, Teune TM, Von Meyenfeldt MF, et al. Preoperative assessment of local tumor extent in advanced rectal cancer: CT or high-resolution MRI? Abdom Imaging 2000;25:533-41.

9. Matheson LJ, Tratnyek PG. Reductive dehalogenation of chlorinated methanes by iron metal. Environ Sci Technol 1994:28:2045-53.

10. Donlan RM, Costerton JW. Biofilms: survival mechanisms of clinically relevant microorganisms. Clin Microbiol Rev 2002;15:167-93.

11. Salman JAS, Al-Marjani MF, Abdulrazaq RA, Salman IAS, Kamil NB. Antibiofilm effect of iron oxide nanoparticles synthesized by Lactobacillus fermentum on catheter. World J Pharm Res 2015;4:1-12.

12. Pramila M, Meenakshisundaram M. Biosynthesis of iron (fe) nanoparticles and its inhibitory effect on Pseudomonas aeruginosa biofilm. Indian J Appl Res 2017;7:251-4.

13. Simoes M, Bennet NR, Rosa EAS. Understanding antimicrobial activities of phytochemicals against multidrug-resistant bacteria and biofilms. Nat Prod Rep 2009;26:746-57.

14. Onsare JG, Arora DS. The antibiofilm potential of flavonoids extracted from Moringa oleifera seed coat against Staphylococcus aureus, Pseudomonas aeruginosa and Candida albicans. J Appl Microbiol 2013;118:313-25.

15. Agbor MA, Naidoo S. Ethnomedicinal plants used by traditional healers to treat oral health problems in cameroon. J EvidenceBased Complementary Altern Med 2015;2:1-10.

16. Bagherzade G, Tavakoli MM, Namaei MH. Green synthesis of iron nanoparticles using the aqueous extract of Musa ornata flower sheath against pathogenic bacteria. Asian Pac J Trop Biomed 2017;7:227-33.

17. Prasad TNVKV, Elumalai EK. Biofabrication of Ag nanoparticles using Moringa oleifera leaf extract and their antimicrobial activity. Asian Pac J Trop Biomed 2011;1:439-42.

18. Latha N, Gowri M. Biosynthesis and characterization of $\mathrm{Fe}_{3} \mathrm{O}_{4}$ nanoparticles using Caricaya papaya leaves extract. Int J Sci Res 2014;12:17.

19. Veerasamy R, Xin TZ, Gunasagaran S, Xiang TFW, Yang EFC, Jeyakumar N, Dhanaraj SA. Biosynthesis of silver nanoparticles using mangosteen leaf extract and evaluation of their antimicrobial activities. J Saudi Chem Soc 2011;15:113-20.

20. Gottimukkala KSV, Harika RP, Deeveka Z. Green synthesis of iron nanoparticles using green tea leaves extract. J Nanomed Biother Discovery 2017;7:151.

21. Vijay Kumar PPN, Pammi SVN, Kollu P, Satyanarayana KVV, Shameem U. Green synthesis and characterization of silver nanoparticles using Boerhaavia diffusa plant extract and their antibacterial activity. Ind Crops Prod 2014;52:562-6.

22. Kanagasubbulakshmi S, Kadirvelu K. Green synthesis of iron oxide nanoparticles using Lagenaria siceraria and evaluation of its antimicrobial activity. Defence Sci J 1994;2:422-7.

23. Prasannaraj G, Venkatachalam P. Green engineering of biomolecule-coated metallic silver nanoparticles and their potential cytotoxic activity against cancer cell lines. Adv Nat Sci Nanosci Nanotech 2017;8:025001.

24. Barapatre A, Aradil KR, Jha H. Synergistic antibacterial and antibiofilm activity of silver nanoparticles biosynthesized by lignin-degrading fungus. Bioresour Bioprocess 2016;3:8.

25. Anju K, Anita Jagadeeswari L, Vidhya Lakshmi D, Nagendra Gandhi N. A review on Indian tribal plants and their biogenic properties. Asian J Pharm Clin Res 2018;11:43-9.

26. El-Assal MI, El-Menofy NG. Chitosan nanoparticles as a drug delivery system for cephalexin and its antimicrobial activity against multidrug-resistant bacteria. Int J Pharm Pharm Sci 2019;11:14-27.

27. Phatak RS, Hendre A. Green synthesis of silver nanorods using aqueous extract of kalanchoe pinnata fresh leaves and its synergistic effect with ciprofloxacin and antibiofilm activities. Int J Pharm Pharm Sci 2015;8:168-4. 